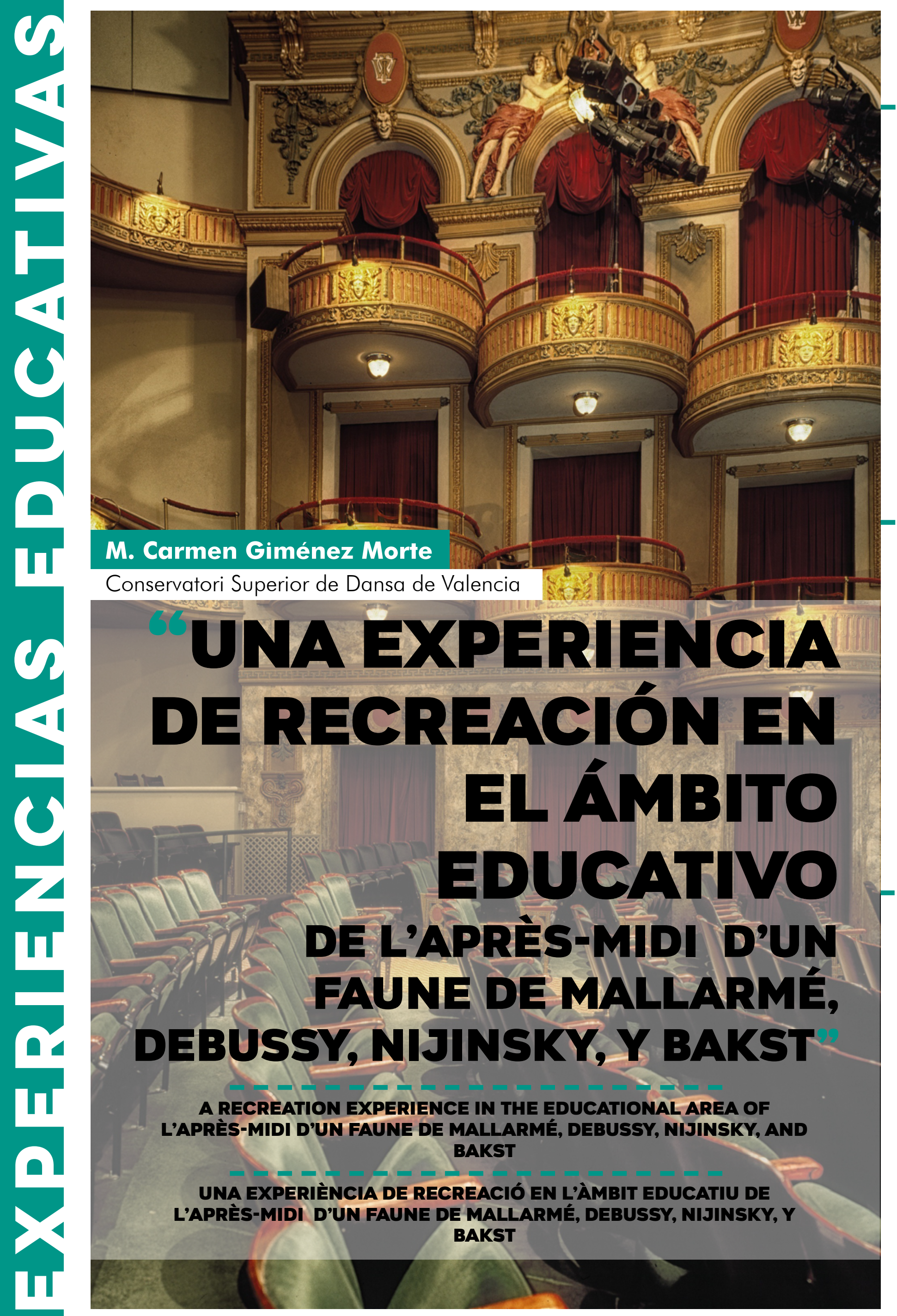


A través de las obras -poema, composición musical, puesta en escena, y vestuario y pintura de telón de fondo-, que conforman L'aprés-midi d'un faune, estrenada en mayo de 1912 en París, se propone un experimento de recreación en el ámbito de las Enseñanzas Artísticas Superiores. La finalidad es que esta experiencia provoque la necesidad de acudir a los documentos históricos como punto de partida de la recreación escénica, a desarrollar la vivencia del cuerpo como archivo de memorias, a ser consciente de la necesidad de la apropiación en el repertorio coreográfico y al cuestionamiento de algunos conceptos clave para comprender el repertorio de la danza contemporánea hoy en día y para relacionarlos con la práctica de danza. La metodología utilizada se entronca con la investigación basada en las artes o performativa, que busca en lo procesos pedagógicos comunitarios la experimentación a través de la experiencia fundamentada. Los resultados tienen como eje central transparentar la vivencia de recreación en el aula, el proceso creativo, e ir generando métodos y estrategias narrativas de la experiencia personal y comunitaria.

\section{PALABRAS CLAVE}

Repertorio, Danza contemporánea, Nuevas pedagogías, Documento, Archivo.

\section{ABSTRACT}

Through the works -poem, musical composition, staging and backdrop painting-, which make up L'aprés-midi d'un faune, premiered in May 1912 in Paris, a recreation experiment is proposed in the field of Higher Artistic Education. The purpose is for this experience to provoke the need to turn to historical documents as a starting point for scenic recreation, to develop the experience of the body as an archive of memories, to be aware of the need for appropriation in the choreographic repertoire and to the questioning of some key concepts to understand the repertoire of contemporary dance today and to relate them to the practice of dance. The methodology used is linked to research based on the arts or performative, which seeks in the community pedagogical processes experimentation through grounded experience. The results have the central transparency of the recreation experience in the classroom, the creative process, and the generation of methods and strategic narratives of the personal and community experience.

\section{KEYWORDS}

Repertory, Contemporary dance, New pedagogy, document, Archive.

\section{RESUM}

A través de les obres -poema, composició musical, posada en escena, i vestuari i pintura de teló de fons-, que conformen L'aprés-midi d'un faune, estrenada al maig de 1912 a París, es proposa un experiment de recreació en l'àmbit de les Ensenyances Artístiques Superiors. La finalitat és que esta experiència provoque la necessitat $d$ 'acudir als documents històrics com a punt d'inici de la recreació escènica, a desenrotllar la vivència del cos com a arxiu de memòries, a ser conscient de la necessitat de l'apropiació en el repertori coreogràfic i al qüestionament d'alguns conceptes clau per a comprendre el repertori de la dansa contemporània hui en dia per a relacionar-los amb la pràctica de dansa. La metodologia utilitzada s'entronca amb la investigació basada en les arts o performativa, que busca en el processos pedagògics comunitaris l'experimentació a través de l'experiència fonamentada. Els resultats tenen com a eix central transparentar la vivència de recreació a l'aula, el procés creatiu, i anar generant mètodes i estratègies narratives de l'experiència personal i comunitària.

\section{PALAULES CLAU}

Repertori, Dansa contemporània, Noves pedagogies, Document, Arxiu. 


\title{
UNA EXPERIENCIA DE RECREACIÓN EN EL ÁMBITO EDUCATIVO DE L'APRÈS-MIDI D'UN FAUNE DE MALLARMÉ, DEBUSSY, NIJINSKY, Y BAKST
}

ש

\section{Carmen Giménez Morte}

\author{
Conservatori Superior de Dansa de Valencia
}

\section{MARCO TEÓRICO Y DEFINICIÓN DE CONCEPTOS}

A lo largo de este texto se van a emplear diversos términos relacionados con el repertorio de la danza contemporánea que es necesario definir previamente y son la base sobre la que se sustenta este experimento de recreación en el ámbito educativo que une la teoría y la práctica.

\section{Repertorio}

El mismo concepto de 'repertorio', que proviene del latin repertorium, se ha empleado para definir, según la primera acepción de la RAE (Real Academia Española de la Lengua), el "conjunto de obras teatrales o musicales que una compañía, una orquesta o un intérprete tienen preparadas para su posible representación o ejecución". Es decir, el conjunto de obras que forman parte de la representación de un intérprete, compañía u orquesta, a lo que podemos añadir, el repertorio de un coreógrafo o coreógrafa a lo largo de su vida artística, o el repertorio de obras de una época determinada, por ejemplo la danza moderna norteamericana de entreguerras; o las obras que por sus características comunes conforman un estilo dancístico. Es por ello, que entendemos que L'après-midi d'un faune (La siesta de un fauno), coreografiada por Nijinsky, forma parte del repertorio de una compañía, en este caso, de los Ballets Rusos de Diaghilev.

Esta experiencia de trabajo teórico práctico sobre una obra clave de la danza escénica de la primera mitad del siglo XX, La siesta de un fauno se encuadra a lo largo del curso 2018-19, en la guía docente de la asignatura Análisis y práctica de obras coreográficas y de repertorio de segundo curso del título superior de danza. Asignatura que pertenece a la materia del mismo nombre, pues así lo determina el currículo de Título Superior en Danza del Conservatori Superior de Dansa de València (CSDV) en la Orden 25/2011, de 2 de noviembre, de la Conselleria de Educación, Formación y Empleo, por el que se establecen y autorizan los planes de estudio de los Centros de Enseñanzas Artísticas Superiores de Danza dependientes del Instituto Superior de Enseñanzas Artísticas de la Comunidad Valenciana (ISEACV). Esta orden desarrolla el currículo de Danza para la Comunidad Valenciana en dos especialidades: Pedagogía de la danza e Interpretación y Coreografía, en los estilos de danza contemporánea, danza clásica, y danza española. A su vez, se divide en cinco itinerarios: Pedagogía profesionalizante, Danza Social, Educativa y del Bienestar, Interpretación, Creación y nuevos medios, y Teoría, cuerpo y escena.

Hay que aclarar que se entiende por danza contemporánea en los planes de estudio del Grado Profesional ${ }^{1}$ y del Grado Superior de este país, tanto a la danza moderna como a la posmoderna y contemporánea. Esto no sucede en las instituciones educativas europeas y americanas, que diferencian claramente por técnicas, estilos y estéticas a la danza moderna de la posmoderna, y éstas son diferentes a la que llaman contemporánea a partir de la dé- 
cada de los ochenta del siglo XX. Tal vez esta mezcla de estilos y estéticas se debe a que en los cuarenta años de dictadura franquista el aislamiento del país impidió que llegaran y se conocieran las nuevas técnicas de danza que se estaban desarrollando principalmente en Estados Unidos y algunos países europeos. Estas técnicas llegaron todas juntas a España a mediados de los años setenta impidiendo distinguirlas claramente.

Por lo tanto, entendemos por repertorio de danza contemporánea a la del siglo XX y XXI. Una vez definido, se comprende como parte fundamental del plan de estudios del grado superior de danza, ya que es una materia dividida en varias asignaturas. Ahora es necesario definir que es patrimonio inmaterial y que entendemos por salvaguardia.

\section{Patrimonio cultural inmaterial}

El repertorio de danza contemporánea lo razonamos como Patrimonio Cultural Inmaterial (PCI) que debe salvaguardarse para las futuras generaciones, según el concepto que utiliza la UNESCO es sus documentos e informes desde la Conferencia General de la Organización de las Naciones Unidas para la Educación, la Ciencia y la Cultura, en su $32^{a}$ reunión celebrada en París en octubre de 2003. Definir que es Patrimonio Histórico Artístico Cultural en el caso de la danza es hablar de PCl. Lo entendemos de este modo ya que "se manifiesta en particular en los siguientes ámbitos: (...) las artes del espectáculo" (Articulo 2, punto 2.b. pag. 2 de documento de la UNESCO), entre las que se encuentra la danza contemporánea.

Por otro lado, en la página web de la UNES$\mathrm{CO}^{2}$ en el apartado ¿ेQué es el patrimonio cultural inmaterial?, aparecen estas frases explicando que es:

\begin{abstract}
"-Tradicional, contemporáneo y viviente a un mismo tiempo: el patrimonio cultural inmaterial no solo incluye tradiciones heredadas del pasado, sino también usos rurales y urbanos contemporáneos característicos de diversos grupos culturales.

-Integrador: podemos compartir expresiones del patrimonio cultural inmaterial que son parecidas a las de otros. Tanto si son de la aldea vecina como si provienen de una ciudad en las antípodas o han sido adaptadas por pueblos que han emigrado a otra región, todas forman parte del patrimonio cultural inmaterial: se han transmitido de generación en generación, han evolucionado en respuesta a su entorno y contribuyen a infundirnos un sentimiento de identidad y continuidad, creando un vínculo entre el pasado y el futuro a través del presente" (página web UNESCO).
\end{abstract}

Se destacan a continuación las ideas que apoyan el posicionamiento adoptado en este relato frente a los procesos de enseñanza aprendizaje del repertorio de la danza, es decir, el repertorio de danza contemporánea es "tradicional, contemporáneo y viviente a un mismo tiempo; es integrador" porque se han transmitido a lo largo del tiempo y en diferentes espacios, pues "ha evolucionado en respuesta a su entorno" y "contribuye a infundirnos un sentimiento de identidad y continuidad". En este caso, la coreografía de La siesta de un fauno de Nijinsky se ha transmitido a lo largo de los siglos XX y XXI, y por lo tanto participa en generar "un vínculo entre el pasado y el futuro a través del presente".

1 Contenidos de la asignatura danza contemporánea en el Grado Profesional de la CV. Las técnicas señaladas como básicas de la danza contemporánea y entre paréntesis, son realmente entendidas como danza moderna norteamericana, es decir, las tres primeras nombradas; y la última es propia de la danza posmoderna.

\footnotetext{
"Práctica de la Danza Contemporánea para adquirir una sólida base técnica que permita un amplio conocimiento de los diferentes estilos. Fundamentos de la técnica de la Danza Contemporánea, con especial énfasis en la flexibilidad de la columna, el sentido del peso y el uso dinámico del espacio. Desarrollo de una sensibilidad estética abierta. Conocimiento y desarrollo de las propias capacidades expresivas. Conocimiento de las diferentes técnicas reconocidas como básicas en el mundo de la Danza Contemporánea (Graham, Cunningham, Limón, Release, etc.). Desarrollo de las habilidades prácticas y técnicas necesarias para adaptarse a la gran variedad característica del repertorio contemporáneo". DECRETO 156/2007, de 21 de septiembre, del Consell, por el que se establece el currículo de las enseñanzas profesionales de danza y se regula el acceso a estas enseñanzas.
}

2 https://ich.unesco.org/es/que-es-el-patrimonio-inmaterial-00003 


\section{Salvaguardia}

El tercer concepto a definir para establecer un marco teórico para esta investigación es 'salvaguardia', y es importante descubrir quienes son los encargados de ello, entre otras instituciones, colectivos y personas individuales, pues como la UNESCO apunta, la viabilidad de su transmisión depende de la enseñanza formal y no formal:

\begin{abstract}
"Se entiende por "salvaguardia" las medidas encaminadas a garantizar la viabilidad del patrimonio cultural inmaterial, comprendidas la identificación, documentación, investigación, preservación, protección, promoción, valorización, transmisión -básicamente a través de la enseñanza formal y no formal- y revitalización de este patrimonio en sus distintos aspectos" (Punto 3 del documento de la UNESCO).
\end{abstract}

Podemos entender que la enseñanza formal y oficial del repertorio de la danza contemporánea hoy en día en España está centrada en los Conservatorios Superiores de Danza, debido a las leyes sobre enseñanzas artísticas que así lo indican desde $1990^{3}$.

A esto se añade que el documento de la UNES$\mathrm{CO}$ en su artículo 14, titulado Educación, sen- sibilización y fortalecimiento de capacidades, establece una especial incidencia en la necesidad de programas educativos de sensibilización, difusión, y formación para asegurar la valorización del $\mathrm{PCl}$. Precisamente especifica que

"Cada Estado Parte intentará por todos los medios oportunos

a) asegurar el reconocimiento, el respeto y la valorización del patrimonio cultural inmaterial en la sociedad, en particular mediante:

1) programas educativos, de sensibilización y de difusión de información dirigidos al público, y en especial a los jóvenes;

2) programas educativos y de formación específicos en las comunidades y grupos interesados;..." (pag. 6).

Dado que el arte de la danza junto con las demás artes escénicas: música, teatro, cine, literatura, no tiene un objeto material que se convierta en obra de arte, en objeto artístico que permita su conservación y exhibición, como ocurre en los museos dedicados a la pintura o la escultura, o que sea posible su salvaguardia

3 A partir de la Ley Orgánica 1/1990, de 3 de octubre, de Ordenación General del Sistema Educativo, también llamada LOGSE (BOE N 238 de 4 octubre de 1990), afecta a todas las Enseñanzas Artísticas, y concretamente, a la enseñanza artística de la Danza que entra oficialmente en el sistema educativo, alcanzando mayor autonomía administrativa con respecto a las enseñanzas de Música y Arte Dramático y disponiendo un currículo de enseñanzas mínimas a cumplir por primera vez en todo el estado español. Se reordena en enseñanzas de grado elemental, enseñanzas de grado medio y enseñanzas de grado superior y, además, la danza se contempla por primera vez como contenido curricular en las áreas de educación artística y educación física de la educación obligatoria.

Por lo que respecta al Grado Superior de Danza, el primer currículo de mínimos se publicó en el Real Decreto 1463/1999, de 17 de septiembre, por el que se establece los aspectos básicos del currículo de las enseñanzas del grado superior de danza y se regula la prueba de acceso a estos estudios [BOE núm. 233 de 29/9/1999].

La Ley Orgánica 2/2006, de 3 de mayo, de Educación, (BOE núm.106, Jueves 4 mayo 2006), introduce algunas novedades importantes en las enseñanzas superiores como, por ejemplo, la intención de situarlas en consonancia con el marco europeo de educación superior.

El RD 632/2010 establece el currículo de mínimos o básico para todo el estado español. Real Decreto 632/2010, de 14 de mayo, por el que se regula el contenido básico de las enseñanzas artísticas superiores de Grado en Danza establecidas en la Ley Orgánica 2/2006, de 3 de mayo, de Educación.

Decreto 48/201 1, de 6 de mayo, del Consell, por el que se establece la ordenación de las enseñanzas artísticas superiores y se determina el marco normativo para la implantación de los planes de estudios correspondientes a los títulos oficiales de graduado o graduada en las diferentes enseñanzas artísticas superiores, en el ámbito de la Comunitat Valenciana. [201 1/5272]

Orden 25/2011, de 2 de noviembre, de la Consellería de Educación, Formación y Empleo, por el que se autorizan los planes de estudio de los centros de enseñanza artística dependientes del ISEACV. Desarrolla el currículo de Danza para la comunidad valenciana en dos especialidades y en cinco itinerarios. 
a través del mantenimiento del objeto material, como por ejemplo, los edificios en el caso de la arquitectura, la transmisión de las obras dancísticas se ha comunicado tradicionalmente de maestros a alumnos, de coreógrafos a bailarines, es decir, de una manera que podríamos llamar oral, sin sistemas de notación o registro, o algún tipo de partitura compositiva. Gerald Siegmund (2010), denomina "memoria comunicativa" a la transmisión oral de la obra coreográfica, y continúan con esta denominación tanto Pouillaud (2009) como De Vallejos (2015).

Se entiende que esta particularidad de la tradición oral de la danza provoca que se diferencie de otras artes escénicas como la música o el teatro que poseen un sistema de notación prácticamente internacional que permite su registro y transmisión con el paso de los años, para salvaguardarlo para las generaciones futuras. No es el caso de la danza, que todavía no cuenta con un sistema de notación internacional plenamente extendido geográficamente, y por tanto, a pesar de los sistemas de grabación audiovisual y digital y de los sistemas de Labanotación para la danza contemporánea o de Benesh para la danza académica, no hay un sistema de notación de los movimientos danzados comparable al de una partitura musical o un texto dramático. Este hecho convierte a la danza en un arte muy frágil de preservar por lo que la "documentación, investigación, preservación, protección, promoción, valorización, transmisión, básicamente a través de la enseñanza formal y no formal", es una responsabilidad de los docentes de la danza, y en general, de los profesionales de este sector.

Apoyando este posicionamiento, en la parte de la página web del $\mathrm{PCl}$ de la UNESCO dedicada a las Artes del espectáculo, extraemos estas frases:

\footnotetext{
"Las medidas de salvaguardia de las artes tradicionales del espectáculo deberían centrarse principalmente en la transmisión de los conocimientos y las técnicas, la utilización y fabricación de instrumentos y el fortalecimiento de los vínculos entre el maestro y el discípulo. Hay que hacer hincapié en las sutilezas de un canto, los movimientos de una danza y las interpretaciones teatrales.
}

La interpretación también puede ser estudiada, grabada, documentada, catalogada y archivada. (...) El proceso de digitalización permite identificar y catalogar debidamente los documentos" (página web UNESCO) .

Dicho en otras palabras, si se comprende que el concepto de danza contemporánea se inicia desde principios del siglo XX para las Enseñanzas Artísticas Superiores en España, si consideramos que el repertorio forma parte de los planes de estudio, que también reúne las suficientes características para ser considerado como $\mathrm{PCl}$, y que los profesores y las instituciones educativas son las encargadas de su transmisión y salvaguarda a través de la documentación, catalogación, y archivo de los documentos, falta todavía determinar como es posible realizar esa transmisión y que metodologías se pueden poner en práctica en el ámbito educativo.

\section{Documento}

Si la UNESCO nos habla de "digitalizar los documentos" para permitir su salvaguarda, hay que especificar que entendemos por 'documento' de una obra de danza contemporánea, y cómo se pueden identificar y catalogar. El diccionario de la Real Academia Española de la Lengua, en su tercera acepción, afirma que documento es una "Cosa que sirve para testimoniar un hecho o informar de él, especialmente del pasado".

En este caso, se va a entender que 'documento' es cualquier material (incluso la interpretación) que "pueda ser estudiada, grabada, documentada, catalogada y archivada", pues informa o testimonia sobre la obra de danza. Por lo tanto, se considera necesario establecer protocolos generales de preservación de documentos de todo tipo que informen o testimonien lo que ha sucedido en el pasado. De este modo se generan archivos de documentos.

Es decir, el concepto de 'documento', de rastro material de algo que ha acontecido, de La siesta de un fauno de Nijinsky será cualquier "cosa" que informe sobre la obra porque la constituye o ha formado parte de ella, entendiendo que la obra de danza es multidiscipli- 
nar: el poema de Mallarmé que ha sido el punto de partida para la música compuesta por Debussy, los telones de fondo y los vestuarios de Bakst, y la coreografía de Nijinsky, son los elementos que consituyen la puesta en escena. Y también se considerarán "documentos" todo el material generado alrededor o posteriormente a la obra que pueda ser "estudiado, grabado, documentado, archivado y catalogado", como por ejemplo, las críticas o artículos de prensa publicados en su estreno, los escritos de cualquiera de los cuatro creadores al respecto de su poema, de la composición musical, de la creación de vestuario y escenografía, y evidentemente, del autor de la coreografía. Y finalmente, la literatura generada sobre esta obra en concreto, es decir, que se ha escrito sobre ella.

\section{Archivo (el cuerpo)}

$\stackrel{m}{=}$ Pero, ¿dónde se encuentran "físicamente" ¿ los archivos de la danza relacionados con la $\therefore$ transmisión, con las técnicas dancísticas y de composición coreográfica, con la interpretación? Aunque este aspecto del repertorio y de su análisis y práctica está en debate hoy en día y se cuestionan diferentes conceptos como por ejemplo, los relacionados con el cuerpo como archivo, la imposibilidad o no de recuperar una obra de danza, y la inevitabilidad de que se incluya necesariamente, aunque no se pretenda, una parte de creación en todo proceso de recuperación de una coreografía. Se va a tratar de explicar a continuación, cual es el posicionamiento respecto a estos asuntos que se han tomado para esta experiencia fundamentada en el ámbito educativo.

La idea del cuerpo del bailarín y bailarina como 'archivo' de Lepecki va directamente relacionada con el concepto de recreación al afirmar que "... los bailarines y coreógrafos contemporáneos de Estados Unidos y Europa han estado activamente implicados en los últimos años en hacer recreaciones (re-enactments) de obras, a veces conocidas, a veces ignotas, de la danza del siglo XX" (Lepecki, 2013. p.61), y explica varios ejemplos desde 2008 de esa mirada vuelta hacia la obra coreográfica del pasado por parte de los coreógrafos y coreógrafas contemporáneos. Concluye que "las actuales recreaciones de la danza se convierten en lugares privilegiados para explorar las relaciones teóricas y coreográficas entre la danza experimental y su deseo de archivo (...) o archivo coreográfico" (Ídem. p.62).
Más adelante cita a Santane para afirmar que "considera a las recreaciones como maneras performativas de teorizar la paradóiica relación del performance art con el documento (...) como contra-memoria y re-documentación" (ídem. p. 64). Y cita a Foucault quien propone "el deseo de archivo como referencia a una capacidad de identificar en una obra pasada campos creativos todavía no agotados de posibilidades impalpables (...) que están siempre presentes en cualquier otro pasado y son los que las recreaciones activan" (Idem. p. 64).

Se adoptan para esta práctica en el ámbito educativo otros conceptos definidos por Gerald Siegmund para afianzar la propuesta de volver la mirada a las obras coreográficas del pasado con un determinado ánimo o finalidad, ya que se cuestiona cual es la obra original: ¿̇la primera que se presentó al público? $\grave{i}$ cada una de las veces en las que la obra se actualiza cuando se produce un acto de comunicación entre los creadores de la pieza coreográfica (creador y bailarines), en un mismo especio y tiempo, y el público?

\footnotetext{
"La danza contemporánea presenta un gran rechazo hacia el paradigma moderno de originalidad, así como a la idea del original auténtico. (...) [gracias a internet] Lo histórico ahora está generalmente a nuestra disposición y es eminentemente citable. (...) La danza contemporánea se ocupa de la historia como un medio de emancipación para el propio bailarín. Se dan a sí mismos su historia. En la práctica de la recreación, la evidente cualidad efímera de la danza que restringe su vida hasta el momento presente da paso a una noción más conflictiva de la temporalidad de las danzas." (Siegmund, 2017, p. 471).
}

Es decir, el concepto del cuerpo como archivo se fundamenta en que "La danza sólo puede encontrar su propio lugar archivístico sobre/ en un cuerpo: el cuerpo entendido como un sistema afectivo de formación, transformación, incorporación y dispersión" (Lepecki, 2013. p. 76). Por lo tanto, la recreación de La siesta de un fauno en unos cuerpos de alumnos de danza en formación, que se van transformando conforme acumulan e incorporan las experiencias de su propia vivencia de formación, y toman, citan, transforman y copian lo que consideran oportuno, va provocando un campo de dispersión en sus cuerpos respecto a la 
obra coreográfica estudiada. Este mismo posicionamiento sobre las transformaciones del cuerpo del bailarín al afectarse por una obra de repertorio de danza contemporánea, es expresada con otras palabras que se ajustan a la idea de afectación o conmoción que provoca el conocimiento de una obra coreográfica en el propio cuerpo. "El afectar o conmover se (...) encuentra su camino hacia nosotros. Por lo tanto, siempre está en una relación de ida y vuelta, un intercambio de espacios; es decir, está hecho de movimiento. La relación entre mi cuerpo y la imagen mental del otro cuerpo que el afectar o conmover promueve es lo que podemos comprender como tránsito; siempre es un proceso cambiante, nunca un objeto o producto fijo". (Siegmund, 2017, p. 478).

\section{Recreación}

Si "En las recreaciones de danza no habrá distinciones entre archivo y cuerpo. El cuerpo es archivo y el archivo es un cuerpo" (Lepecki, 2013, p. 65), ¿̇que hace el cuerpo cuando ha corporeizado, encarnado, (embodiment) la coreografía? ¿En que consiste entonces la recreación de la obra? Franco teoriza la recreación como una práctica de temporalidades asimétricas, y concluye debatiendo la idea de Ricoeurs del documento como rastro, a la vez que cuestiona la idea de la recreación en la danza "como una forma de conocimiento histórico" (Franko 2017). Lepecki coincide con Marck Franko cuando dice que lo que debe ser recuperado no es la coreografía, sino los estados del cuerpo, lo que llamamos corporeizar (Vallejos, p. 169-170).

Este término ya ha aparecido en los párrafos precedentes y también al citar a Gerald Siegmund (2010), que nombra dos modos de trabajar con el proceso de enseñanza aprendizaje del repertorio de danza. Una sería la basada en la transmisión oral, en la relación interpersonal, denominada memoria comunicativa; y una segunda fundamentada en la memoria cultural basada en el trabajo de archivo. Actualmente se debate entre estos dos modos de transmisión del repertorio de la danza con los términos de reconstrucción y de recreación, dependiendo de las creencias, intenciones y finalidades que se tengan respecto a "la obra original".
Podemos definir la restitución o reconstrucción de una obra coreográfica de repertorio como una creación que se presenta a sí misma como capaz de reconstruir una obra del pasado de una manera acabada. Su objetivo íntimo es "tomar el lugar de la obra", reemplazarla. Por otro lado, el término recreación supone la imposibilidad de restituir al público la obra "original", es decir, se asume que se va a proponer una nueva creación o reinvención de la obra coreográfica tomando diversas fuentes, materiales, archivos o documentos históricos y las fuentes en las que se inspiró durante el proceso creativo, como explica Fréderic Pouillaude (2014, p. 271-272) y De Vallejos (2015). ¿Cómo sería o en que se fundamentaría la recreación de La siesta de un fauno en esta experiencia educativa?

Por otro lado, volviendo a los documentos de la UNESCO sobre $\mathrm{PCl}$, cuando en su página web se trata el tema de la transmisión, estas palabras nombran la "recreación" como una necesaria manifestación de la práctica artística que está en constante evolución y no permanece fija, inmóvil, idéntica a ese supuesto "original", que tal vez en las artes temporales sin sistemas de notación o partituras de movimiento, no exista:

\footnotetext{
"Nuestro Patrimonio Cultural Inmaterial (PCl) está siendo recreado constantemente por su depositarios, y los expertos afirman que no hay dos manifestaciones de una sola y misma práctica o expresión que sean totalmente idénticas. Los elementos del $\mathrm{PCl}$ evolucionan constantemente, de una manifestación a otra y a la vez son transmitidos de una persona a otra y de generación en generación.
}

Salvaguardar el PCl equivale a garantizar su viabilidad entre las generaciones actuales y su transmisión a las futuras. Las comunidades y grupos de profesionales y otros depositarios de la tradición en todas partes del mundo han desarrollado sus propios sistemas para la transmisión de sus conocimientos y técnicas, que la mayoría de las veces depende - o, desgraciadamente, dependía - de la tradición oral más que de los textos escritos" $^{\prime 5}$ (página web UNESCO). 


\section{METODOLOGÍA}

Se entronca la metodología empleada en este experimento educativo con las nuevas pedagogías y con las llamadas por algunos autores 'investigaciones postcualitativas', relacionadas con la investigación basada en las artes o investigación performativa.

\begin{abstract}
"Las nuevas ontologías exigen desplazamientos metodológicos, accidentes, saltos conceptuales y deslizamientos, así como detenciones teóricas. Como han argumentado Jacson y Mazzei (2012), Koro-Lujungberg et al. (2009), Koro-Lujungberg (2015) y Lather (2007), las teorías y metodologías están interconectadas para posibilitar relaciones prácticas" (Calderón y Hernández, 2019, p. 56).
\end{abstract}

La investigación performativa trata de generar comprensión y transparentar los métodos empleados durante el proceso de investigación por medio de estrategias narrativas de la experiencia personal y colectiva. Se trata de transparentar los procesos, la estructura y los resultados, y es imprescindible definir los conceptos empleados. La investigación artística es singular, subjetiva, y cuestionable, por lo que es fundamental poder acceder a sus procesos para garantizar su comunicabilidad. La clave está en adquirir conocimiento a través de la práctica. "Aproximarse al proceso (...) llama la atención sobre el interés que ha cobrado conocer, hacer pública y compartir la trayectoria de pensamiento que han seguido quienes han esbozado o llevado a cabo una propuesta artística"(Calderón y Hernández, 2019, p. 10). Por ello, se propone un trabajo colaborativo fundamentado en el aprendizaje cooperativo de los grupos formados por el alumnado.

Sería lo que Fernández llama experiencia fundamentada que relata las relaciones que demuestran la participación en un proceso creativo ya que se trata de aprender dialógica y vivencialmente a través de la experiencia por medio del diálogo reflexivo y el aprendizaje en comunidad.

"El fenómeno dancístico, por tanto, no solo es una experiencia individual, sino intersubjetiva del mundo y de sus infinitos modos de darse; se muestra desde múltiples perspectivas que permiten la constitución de la obra dancística como un proceso en el que no solo hay representación y experiencia desde diversos niveles, sino también aprendizaje, ejecuciones, recepción, reflexión y descripción. (...) cada danzante que ejecuta movimientos idénticos a los realizados por otros, no expresa lo mismo; los espectadores perciben la diferencia y completan con su compromiso la obra de arte que es la danza" (López-Saenz, 2018, p. 479).

Se trata de provocar vivencias de aprendizaje comunitarias en los alumnos de la asignatura Análisis y práctica de obras coreográficas y de repertorio de segundo curso, para que les permita reflexionar sobre la práctica del repertorio de danza contemporánea. El fin es practicar los conceptos descritos al inicio de estas páginas y comprenderlos a través de la práctica, que no necesariamente debe destilar un producto artístico, pero sí experiencias de indagación propias del movimiento postcualitativo a través del imaginario de cada uno de los participantes en la experiencia fundamentada:

\footnotetext{
"Somos epígonos que dialogamos con lecturas, imágenes, obras artísticas generadas en tiempos y culturas diferentes, que van nutriendo nuestro imaginario (...) es con ese imaginario, que siempre es colectivo, pero que se articula desde las biografías y experiencias de cada cual con el que nos ponemos en relación de manera consciente o desde la huella que ha dejado en nuestro cerebro, en lo que hoy se denomina "nuevo inconsciente"...". Esta idea cambia a partir de 2015 con Van Heusden y Gielen "... no tienen por qué ser obras artísticas. Pueden ser acontecimientos y experiencias de indagación" (Calderón y Hernández, 2019. p. 11).
}

Las obras de repertorio de danza contemporánea se analizan y practican a lo largo de los tres primeros cursos de la titulación superior en danza, siempre con la idea final de buscar nuevas metodologías y de investigar sobre la práctica artística entendida como investigación artística y como generadora de conocimiento.

"... Hay que distinguir entre investigación dentro del arte e investigación para el arte. La investigación para el arte es la que se hace para producir una obra de arte. Eso no nos ocupa aquí pero sí la primera: la investigación dentro o a través de las artes, que estaría o está en paralelo o es análoga a la investigación artística, pero a la vez 
diferente, y se trata por tanto de otra forma de producción cognitiva" (Villar, p. 207).

Para finalizar este apartado, se ha tenido en cuenta que se considera que las metodologías de investigación para la salvaguardia del patrimonio inmaterial están en construcción, ya que la UNESCO especifica que es necesario "fomentar estudios científicos, técnicos y artísticos, así como metodologías de investigación, para la salvaguardia eficaz del patrimonio cultural inmaterial" (Articulo 13.c. de la UNESCO. p. 6).

\section{PROPUESTA EN EL ÁMBITO EDUCATIVO}

El nuevo paradigma de las enseñanzas artísticas superiores que centran el aprendizaje en el alumno, propone unas metodologías de enseñanza-aprendizaje basadas en la práctica y en los intereses y saberes de los estudiantes, por lo que la adaptabilidad y el desarrollo de las capacidades y competencias son los pilares fundamentales de cada una de las sesiones de esta asignatura.

En esta asignatura de segundo curso, se proponen a lo largo del curso diversas experiencias de reconstrucción y recreación del repertorio de danza del siglo XX dirigidas por la profesora 6 , y en las que participan activamente los alumnos con propuestas artísticas y con una pequeña experiencia de iniciación a la investigación con la búsqueda de materiales y documentos sobre la obra coreográfica. Estas páginas tratan de relatar los pasos seguidos en la reconstrucción de La siesta de un fauno de Nijinsky durante el curso 2018-19 con los alumnos de segundo curso del $\mathrm{CSDV}^{7}$, durante tres horas semanales a lo largo de cinco semanas, combinando sesiones teóricas y prácticas.
Como la materia se divide a lo largo de tres cursos, durante el primer año de la titulación, en la asignatura de Movimientos y tendencias, se dedican tres sesiones a la aproximación a estos materiales o hitos que van a ir construyendo el mapa de memoria de la materia. El objetivo se centra en las intenciones y actitudes que sabemos que Ninjinsky tenía y que escribió en su Diario, durante el tiempo de creación del Fauno, por ejemplo: "yo trabajaba en un sistema de notación para la danza (...) y quería olvidarme de mi mismo y empezar a transcribir mi ballet Fauno siguiendo este sistema" (p. 104) y más adelante, en relación a la polémica en la prensa, explica que "Calmette era un crítico muy conocido, que además escribía sobre política. Escribió una crítica infame de L'après midi d'un faune diciendo que era indecente. Cuando yo compuse este ballet no tenía pensamientos perversos. Disfruté durante su creación" (p. 1 18). Estas citas son el primer documento o hito del mapa de memoria que se realiza en primer curso.

Durante el primer curso, también se han trabajado algunos conceptos de composición empleados en esta pieza de Nijinsky, como son la inspiración de formas corporales basadas en las pinturas de vasijas, estatuas y bajorrelieves griegos y romanos, y el caminar con el cuerpo en tres cuartos, como si se bailara en un estrecho pasillo, emulando ser una figura conectada con el fondo de un bajorrelieve.

En segundo curso se inicia la experiencia con una presentación teórica oral en la que se contextualiza la puesta en escena de esta danza y se explican cada una de las obras que componen La siesta de un fauno, a la vez que se introduce a los artistas que confluyen en esta pieza de danza: el poema de Mallarme, la composición musical de Debussy, la coreografía de Nijinsky, y la pintura del telón de fondo y el

6 Las experiencias previas sobre recreación en las aulas de los Centros Superiores de Danza se insertan en el trabajo desarrollado por el grupo de investigación financiado por el ISEACV en las convocatorias de 2016-18 y 2018-20, cuyos títulos son, para el primer bienio: Reflexión sobre los conceptos de versión, apropiación, adaptación, recreación y reconstrucción en las artes escénicas (danza y teatro) y estrategias para su aplicación en la práctica docente en las Enseñanzas Artísticas Superiores. En este momento nos encontramos en el segundo año de la investigación del segundo proyecto titulado CREARED-ESCENA: Proyectos de colaboración artístico-educativa transdisciplinar y de salvaguarda del patrimonio del teatro y la danza .

7 Esta investigación ha sido posible gracias a los alumnos y alumnas de $2^{\circ}$ curso de la especialidad de coreografía e interpretación de danza contemporánea del Conservatori Superior de Dansa de València, durante el curso 2018-19: Celia, Irene, Carla, Carolina, Iván, Mariam, Blessing, Illya, Johhanna, Laura. 
vesturario de Bakst. Estos cuatro elementos van a ser tratados como documentos en los que basarse para realizar la recreación de danza.

La primera sesión práctica consiste en establecer unos conceptos sobre la obra de repertorio que cuestionan la posibilidad de reproducir o de recrear fielmente la puesta en escena para establecer un debate en el grupo de clase. Si consideramos que es posible volver a traer a la vida la historia, estamos aceptando que podemos restituir la obra coreográfica y por tanto un análisis exhaustivo de su estructura general, de su estilo compositivo, de los elementos de la puesta en escena (música, coreografía, iluminación, movimiento de bailarines, vestuario y escenografía), y del lenguaje de movimiento codificado o no, nos aportarán los elementos fundamentales para comenzar a aprehenderla.

\begin{abstract}
"Educar es hacer pensar y hacer que el sujeto descubra y tome conciencia de las posibilidades transformadoras que posee en el ambiente natural y social que le tocará vivir (...) se estimula al alumno/a a preguntar, criticar y crear (...) Considera lo cognoscitivo y lo emocional como elementos inseparables en su juicio. Estudiamos, aprendemos, enseñamos y conocemos nuestro cuerpo entero con los sentimientos, con las emociones, con los deseos, con los miedos, con las dudas, con la pasión y también con la razón crítica" (De la rosa y alt. p. 60-61).
\end{abstract}

Esta mirada vuelta hacia la historia de las artes, además de contextualizar la participación de estos artistas y la sociedad en la que se inscriben los documentos artísticos, ayuda a definir algunos conceptos importantes para el repertorio de la danza contemporánea.

“... el número cada vez mayor de protocolos múltiples de reconstrucción, repetición, revivificación y re-doing (este último difiere del re-enactment, en que hay un mayor grado de libertad en el proceso de adaptación) existente en estos tiempos, parece confirmar este argumento. [...] cada una de ellas [de las versiones o recreaciones] con distinto número de participantes, distribución, duración, ubicación espacial, etc. [...] Estos proyectos colectivos [...] proporcionan ejemplos explícitos del potencial que revelan las reposiciones y de la apropiación en la era posmoderna". (Formis 2017, 87-88).
A la vez, esta mirada hacia la historia permite reflexionar sobre otros conceptos referidos al repertorio de la danza contemporánea, actualizándolos a través de las vivencias para procurar su supervivencia y transmisión a las jóvenes generaciones. Ana María Guasch, cuando explica la influencia del pensamiento de Derrida en la obra de Pedro G. Romero habla de huellas, de rastros del pasado como una memoria que "sobrevive de una manera consciente en el aquí y ahora de nuestro conocimiento" (2015, 247). Esa idea es inspiradora para reflexionar sobre cuales son los documentos de la danza que existen en el propio cuerpo como archivos de vivencias, de movimientos y técnicas apropiados a lo largo de los años de práctica.

Seguidamente se presentan a los alumnos algunos documentos que se generan a partir o alrededor de la obra, como son los dos artículos de prensa sobre el estreno de La siesta de un fauno, el pasaje sobre la creación de esta obra extraído del libro que escribió la mujer de Nijinsky sobre su vida, el diario del coreógrafo, y otros materiales encontrados por los alumnos en internet. En ese momento se propone un experimento, una experiencia, en la que supuestamente cada grupo de alumnos debe recrear la obra partiendo sobre todo de uno de los elementos que la conforman en escena y que han participado en la poética o proceso creativo: el poema, el vestuario y la escenografía, la coreografía y la música. La idea es que los alumnos gestionen con las dos temporalidades, la presente y la histórica, y que tomen sus propias decisiones sobre el tiempo, el espacio, la narrativa, y el gesto y el movimiento en el proceso de recreación.

\footnotetext{
"La recreación de la danza siempre está enredada en temporalidades superpuestas, gracias a lo cual la noción del tiempo histórico se desestabiliza, por una historicidad incierta que depende del gesto, a medida que se convierte en narración. Una de las características de la recreación de la danza es que la historicidad siempre se invierte en temporalidades complejas cuyas modalidades están más relacionadas con la espacialidad que con la narrativa". (Franko, 2017, p. 2).
}

Es decir, si el archivo es la coreografía aprendida o la puesta en escena de una obra dancística que conocemos previamente, ¿̇qué sentido tiene tratar de reproducirla en el aquí y ahora cuando han cambiado las personas que la ge- 
neraron en un contexto social, cultual y político muy concreto? ¿̇qué es visible todavía y que se ha perdido? ¿̇qué partes de los documentos se han destruido y cuales se recrean aunque no sea esa la intención? "Se trata, pues, de un archivo que se mueve entre lo visible y lo invisible, entre lo ausente y lo presente, entre la destrucción y construcción, entre el caos y el orden" (Guasch 247).

Con esas preguntas resonando en el aula, se pone en conocimiento de los discentes algunas de las numerosas versiones que se han realizado a lo largo de la historia de la danza en el siglo $X X^{8}$, desde el estreno de Nijinsky en 1912, y se visualiza a través de youtube la reconstrucción del estreno de 1912 realizada por la Opera de París y bailado por Charles Jude como fauno y Marie Claude Pietragalla como ninfa, y posteriormente con la de Rudolf Nureyev, ya que se encuentran fácilmente en youtube. A continuación se lee el poema de Stéphane Mallarmé y se escucha la música compuesta por Debussy. Se observa el telón de fondo de Bakst proyectado a gran tamaño en el aula y se trata de describir el vestuario de las ninfas y del fauno. Seguidamente se visualizan las treinta y tres fotografías del Barón Adolf de Meyer de L'après midi d'un faune realizadas en 1912, y publicadas por Dance Books Ltd. en 1983, que se tratan como una aproximación a la documentación histórica. Se trata a cada una de estas obras como un documento de referencia sobre el que partir para realizar la recreación del Fauno.

Se incide en la idea desarrollada por Álvarez Puente que se pregunta hasta donde la danza se ha fundamentado en la recreación de la memoria y explica que

\footnotetext{
"se puede alcanzar una autenticidad crítica de las obras que refleja un efecto estético, mientras que se conozcan las propiedades constitutivas de las obras. Por otro lado, debido a la falta de documentación fundamentalmente coreográfica, la autenticidad histórica, la cual está basada en la recuperación de las características formales y el origen de las piezas, es prácticamente imposible" (2012, p. 251).
}

La segunda fase, la práctica, consiste en formar cuatro grupos de alumnos y alumnas con los once estudiantes que cursan la asignatura, (dos grupos con dos alumnos, y otros dos con tres, mientras que una alumna no participa por encontrarse lesionada) para que trabajen cada uno de los documentos propuestos: el poema, la música, la coreografía, y la pintura. Se inicia la sesión con una puesta en común de la documentación encontrada por los alumnos después de una búsqueda de materiales en internet y en diferentes bibliotecas como la de la facultad de Bellas Artes, el Centro de Documentación del Instituto de Cultura de la Comunidad Valenciana, y la biblioteca del centro educativo. A partir de este momento, cada grupo trabaja con independencia de los demás con la labor de la profesora como de guía y acompañamiento durante este proceso de trabajo creativo. El pianista acompañante de esta asignatura, Jesús Serrano, participa en el grupo que trabaja con la partitura musical, o con cualquiera de los otros grupos que lo necesite. Finalmente, el último día, se realiza una muestra a los compañeros y compañeras del trabajo realizado y se crea un grupo de discusión para debatir los hallazgos y las fallas de cada una de las propuestas de recreación.

\section{LOS DOCUMENTOS: POEMA, MÚSICA, COREOGRAFÍA, PINTURA DEL TELÓN DE FONDO Y VESTUARIO} Mallarmé escribe el poema en 1876, donde narra los deseos del fauno por las ninfas, quedándose dormido mientras reconoce su fracaso amoroso. Perteneciente a la corriente del simbolismo francés, también es considerado pionero de las vanguardias, como el impresionismo, por las imágenes, visiones fantásticas, y ambientes paganos soñados, que logra expresar con sus palabras, y construir símbolos con variados significados. Construye el poema alrededor de una idea o símbolo inicial, un recurso creativo que se repite en la construcción de algunas coreografías contemporáneas. Interesan los recursos literarios empleados en su poema versionado para la escena plenos de juegos poéticos y que se trasladan, se traducen, en movimientos dancísticos.

Preludio a la siesta de un fauno es el título de la composición para orquesta de Claude Debussy inspirada en este poema, estrenada en París en 1984, y que es considerada una de las obras del compositor que refleja mejor el

8 Entre otras: Lifar, 1935; Robbins, 1953; Joos, 1965; Bejart, 1987; Malandain, 1995. 
espíritu impresionista por la sonoridad misteriosa que logra con sus acordes iniciales. En varios momentos, la composición se asemeja a la estructura rítmica del frenesí amoroso, pues se inicia suavemente con un pianissimo y va creciendo progresivamente, hasta alcanzar el clímax, para posteriormente ir disminuyendo poco a poco hasta el silencio. Su estructura es A B $A^{\prime}$ y una coda, y cada una de las partes basada en una única melodía: la melodía del fauno, su frenesí amoroso, el clímax frustrado, y la coda o siesta (Fernández, blog).

La coreografía de Nijinsky se aprende a fragmentos para sentir en el propio cuerpo algunos de los movimientos característicos del estilo de esta pieza. Estos movimientos los elige el grupo de alumnos ya que se trata de no perder el espíritu, la energía y el sentido del movimiento y de cada una de las cortas frases coreográficas que se tratan como "citas" de la obra de Nijinsky, y que se insertarán en los "textos coreográficos" o "partituras de movimiento" que crearán cada uno de los grupos de alumnos y alumnas.

Los movimientos propuestos para esta obra no provienen de la danza académica pues:

\footnotetext{
"La coreografía novedosa y pionera de Nijinsky toma como punto de partida el cuerpo del bailarín, con sus movimientos internos y externos, y pone su figura corpórea en relación espacial, dinámica y emocional con los demás bailarines. En el centro de la escena se mueve el cuerpo de danza, liberado de los dictados de la cción de la escena teatral concebida literariamente, elaborando a partir de sí mismo un vocabulario de movimientos independiente". (Gabner, 2009, 35).
}

Respecto al telón de fondo pintado por Bakst, el uso de los colores brillantes y la abigarrada ocupación del espacio del telón de fondo, ofrecen una especie de camuflaje a los seres fantásticos que pueblan el espacio coreográfico. El vestuario de las ninfas destaca por sus referencias formales a las túnicas griegas de los bajorrelieves helenos, y el del fauno se inscribe en la idea de manifestar, a través de las manchas que imitan a las de los animales, la deshumanización del rol del bailarín. Los Ballets Rusos de Diaghilev presentan producciones imaginativas, sensuales donde se trabaja en el mismo equipo todos los artistas, pintores, coreógrafos, compositores... Bakst es uno de los más fieles colaboradores de esta compañía, llegando a lo exótico y oriental en algunos ballets. En algunos casos,

"Si las formas rotundas y envolventes de Bakst invocaban a una sociedad hostil a la expresión privada, sus espacios, anhelantes ante la promesa de placeres secretos, y sus colores -cálidos, vívidos, intensos- elevaban las emociones del dramatismo (Garafola 2000, 40).

\section{RECREACIÓN DE LA SIESTA DE UN FAUNO DE NIJINSKY, MALLARMÉ, BAKST Y DEBUSSY}

A partir de los materiales que formaron parte del resultado artístico de La siesta de un fauno se construyen rutas creativas, una por cada grupo de alumnos. Estos materiales son: Poema de Mallarme, Música de Claude Debussy, Decorados y vestuario de León Bask, movimiento coreográfico de Nijinsky, que fueron las fuentes del proceso creativo, y desde los que se propone un camino de acercamiento a la recreación con la idea de dejarse afectar, de reconstruir, recrear, y corporeizar algunos fragmentos o frases coreográficas de esta obra de repertorio estrenada hace más de cien años.

Se explican los conceptos básicos junto con la idea de entender la danza contemporánea como parte del patrimonio inmaterial según la UNESCO. Se leen y se trabaja extrayendo las principales ideas de varios artículos que han localizado los alumnos y alumnas fácilmente en internet sobre la obra. Se informa al alumnado del proceso de investigación y se le solicita el consentimiento informado. Se finaliza la sesión hablando sobre la polémica entre Gastón Calmette y Rodin, denostando y apoyando respectivamente con sus críticas el estreno de esta obra, como nos cuenta en el capítulo que dedica su mujer Rómola a La siesta de un fauno en la publicación sobre la vida de Nijinsky.

En la segunda sesión se comienzan a trabajar en grupos separados entre sí, cada grupo en un aula diferente, y se continúa durante varias sesiones hasta que, una vez finalizado, se presenta el trabajo resultante de la recreación en una última sesión, y se realiza la evaluación. Se muestran a continuación las decisiones del grupo de alumnos que durante cinco sesiones del primer trimestre de 2018-19, han trabajado en la elaboración del mapa de memoria 
que se ha construido a través de las anotaciones en el cuaderno del profesor/investigador.

\section{Grupo 1. Mapa de memoria y metodología sobre la música.}

\section{Figura 1. Partitura del Preludio a la siesta de un fauno}

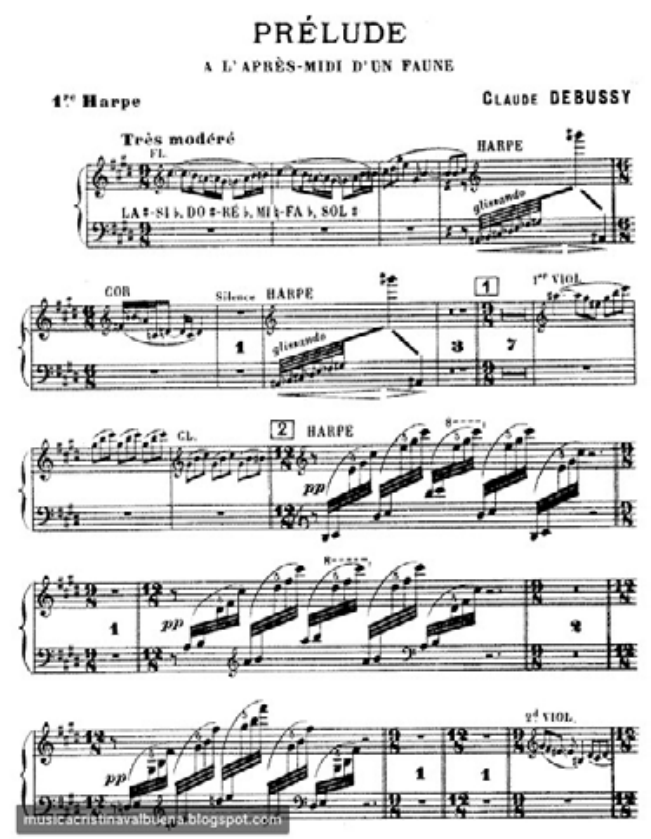

Realizan junto al pianista acompañante Jesús Serrano un escueto análisis musical de la obra y de los recursos musicales impresionistas para trasladarlos al movimiento propuesto. En las sesiones se trabaja estrechamente con la pianista acompañante. Se decide trabajar con el diseño de la partitura musical como elemento gráfico y en algunos símbolos abstractos de la partitura, para emular los recorridos espaciales y los recorridos de diferentes partes del cuerpo como pautas de improvisación de movimiento, para ir construyendo las frases coreográficas.

Figura 2. Alumnas presentando el trabajo de recreación basado en la música

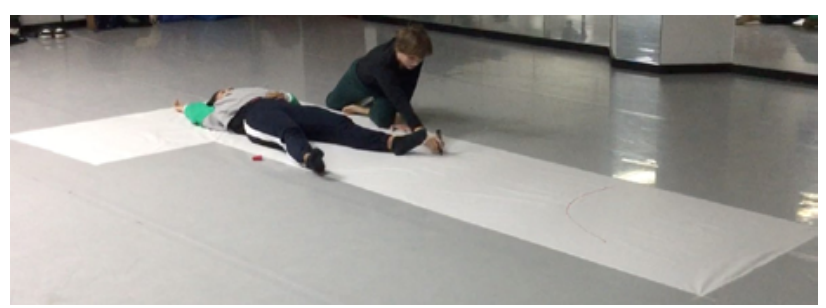

Estos dibujos espaciales son realizados en el suelo que ha sido cubierto con un papel grande para poder dibujar el espacio ocupado por el cuerpo. Se toman tres movimientos como citas de la coreografía de Niijinsky, basadas en la reconstrucción de la obra: la posición de tumbado en el suelo, los cambrés y las miradas entre las ninfas. No han repartido roles entre ninfa y fauno, es una propuesta conceptual. Se juega con las intensidades y se realizan algunos cambios a lo propuesto por la partitura musical. No dan importancia al vestuario.

\section{Grupo 2. Mapa de memoria y metodología sobre el movimiento.}

\section{Figura 3: Alumnos en la recreación basada en el movimiento coreográfico.}

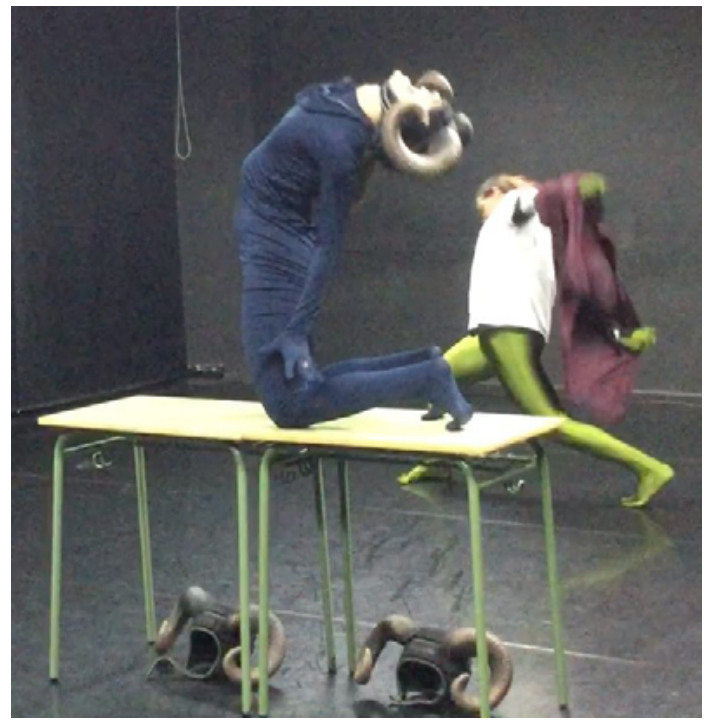

Se trabaja sobre la búsqueda del caminar no humano pues era uno de los mayores intereses de Nijinsky. A través del visionado del audiovisual se eligen algunas poses a modo de "citas literales de movimiento" (la posición del fauno de recostarse con una rodilla doblada; la boca abierta desmesuradamente; el caminar de talón y punta; las manos rotas por las muñecas, con el pulgar muy separado de los otros cuatro dedos extendidos y muy juntos; el girar la cabeza de izquierda a derecha con movimientos fragmentados y secos; el salto con las piernas dobladas del fauno). Para lograr el efecto de cita, a cada una de las poses le precede y sucede un black out, es decir, la iluminación se utiliza como recurso compositivo. Además, se piensa reconstruir algunos de los movimientos de la coreografía secuenciados en frases 
coreográficas cortas, por ejemplo, las ninfas agitan los antebrazos rápidamente y se van; posiciones de los brazos mientras se camina; recorridos espaciales laterales. Y finalmente, con la descripción de los movimientos del bailarín que escribió Rodin y se publicó en el diario Le Matin en primera página:

"En este ballet no hay saltos o brincos; tan sólo actitudes y gestos de una animalidad semiconsciente; se extiende, se encoge, mima agazapado, se incorpora, se adelante y retrocede, con unos movimientos ora lentos, ora bruscos, nerviosos y angulosos; su mirada acecha, sus brazos se extienden en el aire, su mano se abre hacia la lejanía, con los dedos apretados; su cabeza se vuelve en una apetencia que él se esfuerza en que sea poco hábil, pero podríamos creer natural. Entre la mímica y la plástica reina un acuerdo absoluto, y todo el cuerpo expresa lo que ha querido expresar el espíritu: posee la belleza del fresco y de las estatuas antiguas;" (p. 181-182).

No quieren usar la música original y buscan otras contemporáneas.

\section{Figura 4: Las dos alumnas y el alumno del grupo que recrean a través del movimiento coreográfico.}

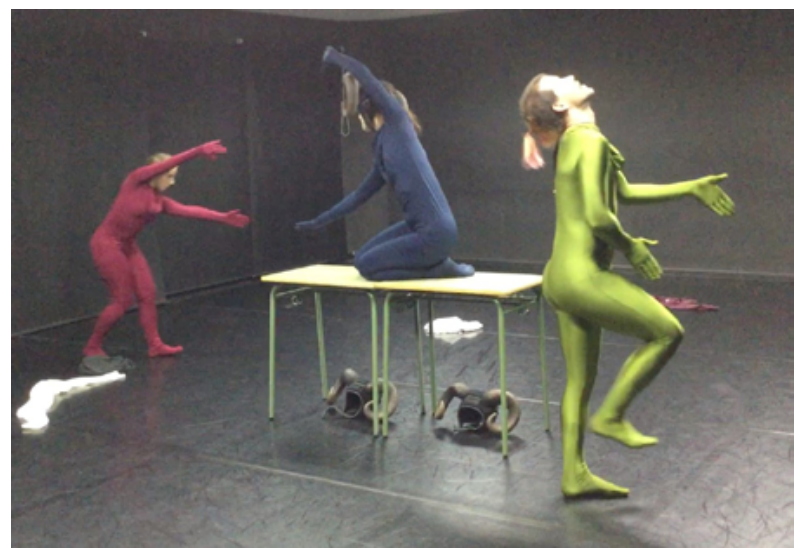

\section{Grupo 3. Mapa de memoria y} metodología sobre el poema

\section{Figuras 5 y 6. Dos alumnas y un alumno en la reconstrucción a partir del poema de Mallarmé.}
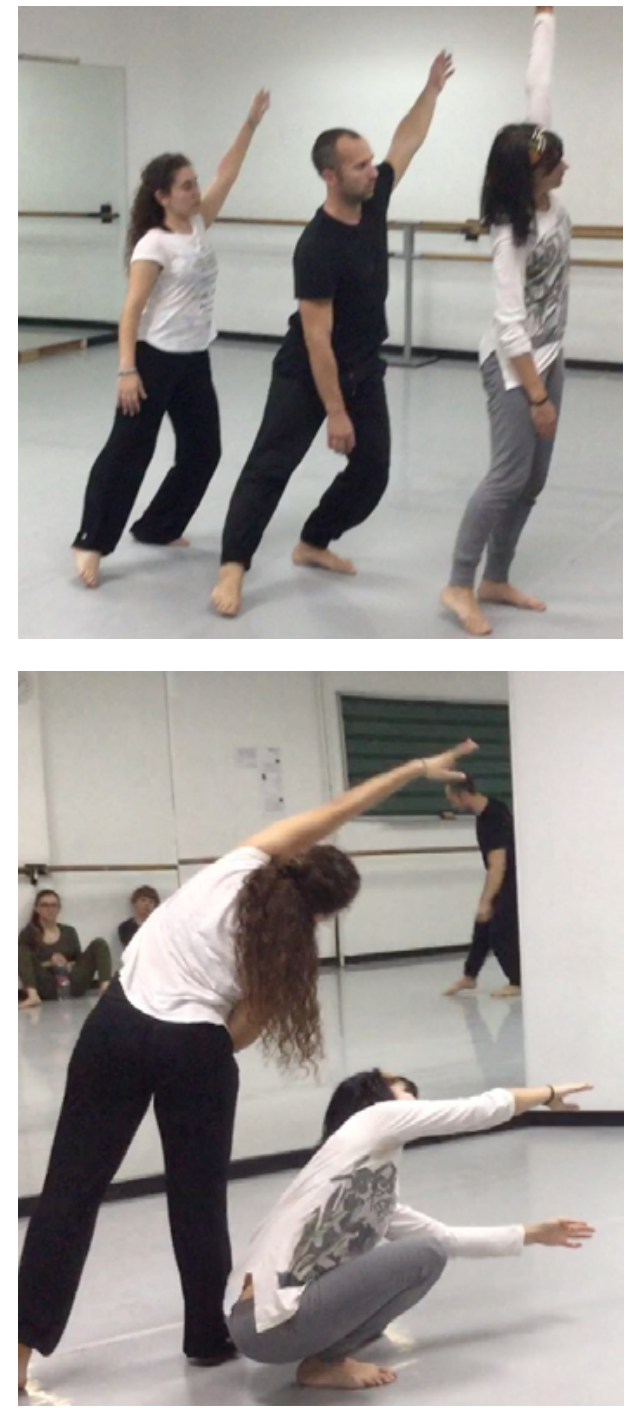

Trabajo de recreación basado en el análisis de las palabras, en las figuras poéticas que aparecen en el poema, como metáforas, metonimias, elipsis y alusiones. Por otro lado, se otorga al fragmento elegido del poema, un movimiento para cada una de las palabras y posteriormente, un movimiento para cada una de las letras. De este modo se van construyendo frases coreográficas que pueden ir fijándose, o no, tanto en el espacio y tiempo como en lo que entendemos por coreografía. Todo depende de lo que se vaya decidiendo en el grupo. Decide el grupo sobre el uso o no de la música de Debussy. Finalmente, el resultado del proceso es que para cada figura retórica han elegido una palabra y una acción. Cada letra es un movimiento. Su propuesta es bailar las letras como si fueran un sistema de notación. Primero se presenta tal cual el movimiento de cada letra, y en una segunda lectura, se presenta la acción que modifica la frase de movimiento generada: 
Alusión: Olvidémoslas- hace referencia a la alusión, es decir, al ser una cita de algo, se queda igual

Elipsis: Compañía- quitan letras/movimientos (en este caso, las vocales)

Metáfora 1: Enredado (cambia el movimiento aunque el significado es el mismo)

Descripcción 1: Granada (se representan las letras, dibujadas en el espacio con alguna parte del cuerpo)

Metonimia 1: Etna (buscar letras/movimientos parecidos, o sustituir uno por otro)

Descripción 2: Cenizas (se representan las letras, dibujadas en el espacio con alguna parte del cuerpo)

Metáfora 2: Torrente (cambia el movimiento aunque el significado es el mismo)

Metonimia 2: Labios (buscar letras/movimientos parecidos, o sustituir uno por otro)

Todas ellas se realizan a través del movimiento y la improvisación en el caso de las metáforas y metonimias en la segunda lectura.

Vestuario blanco, negro y gris, tratando de emular la tinta negra sobre papel característica de la escritura.

\section{Grupo 4. Mapa de memoria y metodología sobre el telón pintado y el vestuario}

\section{Figura 7: Telón pintado de León Bakst para La siesta de un fauno.}

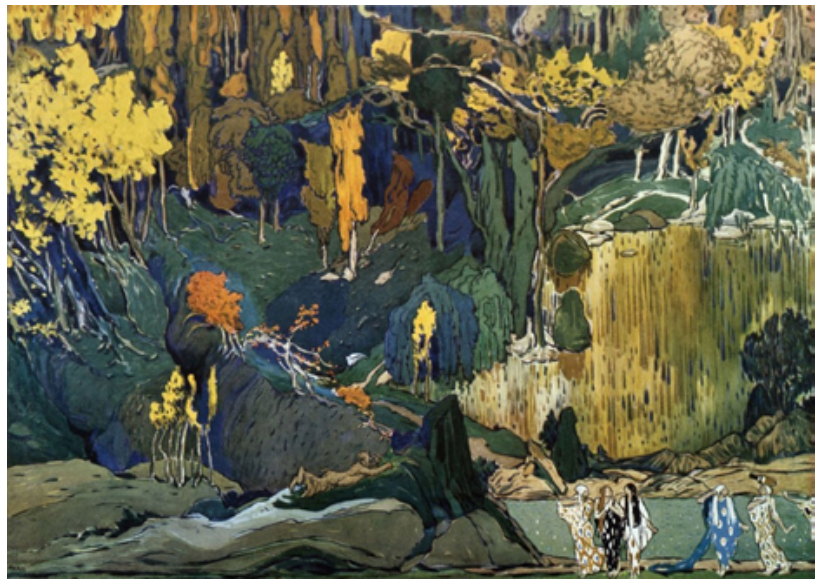

Los fundamentos teóricos extraídos del libro La espiritualidad en el arte de Kandinsky para trabajar el significado de los colores, y del manual de Rudolf Arheim titulado Arte y percepción visual. Psicología del ojo creador, son las bases para descubrir el significado de las formas en relación a los contextos, y de los procesos de conceptualización de la percepción del telón de fondo pintado por Bakst. Se decide después de la lectura de algunos fragmentos de estos textos que el fundamento de la recreación se centrará en la búsqueda de significados entre la relación del verde, entendido como el color de la naturaleza y que identifican con las ninfas, y el amarillo, que se relaciona con la energía, la liberación, y que correspondería con el fauno. Después de un extenso debate, deciden mantener esta dicotomía de color, pero no van a designar roles a cada uno de los componentes del grupo, simplemente sirven el verde y el amarillo para reunir determinadas cualidades de movimiento y niveles en torno a los colores.

Figura 8. Las alumnas recreando a partir de los colores del telón pintado de Bakst.

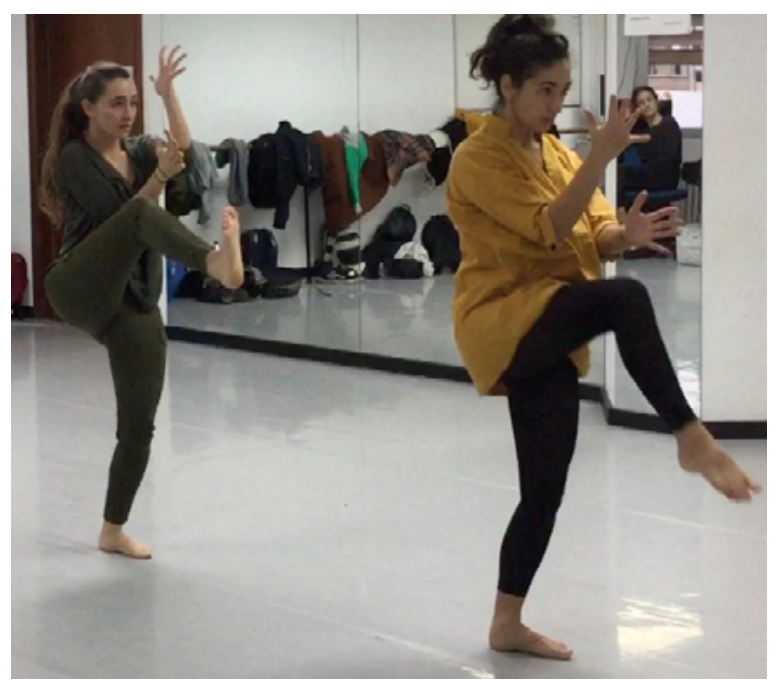

El verde se utiliza para el nivel bajo, y el amarillo para el nivel alto, ya que esos son los colores dominantes en el telón pintado en cada uno de los niveles. Espacialmente mantienen la idea de movimiento en bajorrelieve como hizo Nijinsky, y por tanto crean un espacio escénico de dos niveles: alto y bajo con las características de los colores. Verde: calma, esperanza. Amarillo: energía, potencia. Respecto al espacio sonoro, combinan sonidos de la naturaleza como el agua de un arroyo y el viento moviendo las hojas de los árboles, con 
la música de Debussy. Al principio el grupo estará unido y se irá separando poco a poco. No hay roles de ninfas y fauno, se fundamentan en la oposición de niveles y en las cualidades de los colores relacionadas con las cualidades de movimiento. Leves referencias a posiciones de manos y pies de la coreografía de Nijinsky, pero tal vez no llegan a ser citas textuales de movimiento, más bien se trata de intentar captar el estilo peculiar de la obra.

\section{CONCLUSIÓN}

Unir la teoría con la práctica se muestra como una estrategia que acerca a los alumnos y alumnas al conocimiento de las obras de repertorio de la danza contemporánea y cuestiona conceptos tradicionales de la puesta en escena. A la vez, permite la vivencia del movimiento danzado, la iniciación a la indagación, y la adquisición, a través de la experiencia fundamentada, de conceptos clave como: repertorio, salvaguardia, documento, archivo, y recreación. Todo ello con el fin de transparentar el proceso creativo y trabajar en comunidad.

\section{OBRAS CITADAS Y DE REFERENCIA}

Álvarez Puente, I. (2012). El arte de recrear: el concepto de autenticidad de la danza en WAA La investigación en Danza en España 2012. (pp. 243-254). Valencia: Mahali.

Calderón García, N. y Hernández Hernández, F. (2019). La investigación artística. Un espacio de conocimiento disruptivo en las artes y la universidad. Barcelona: Octaedro.

Convención para la salvaguardia del Patrimonio Inmaterial. París, 17 de octubre de 2003. Https://ich.unesco.org/es [consulta: 15 septiembre 2019].

Decreto 156/2007, de 21 de septiembre, del Consell, por el que se establece el currículo de las enseñanzas profesionales de danza y se regula el acceso a estas enseñanzas. http://www.dogv.gva.es/ datos/2007/09/25/pdf/2007 11704.pdf [consulta: 18 septiembre 2019].

De Vallejos, I. (2015) El cuerpo archivo y la ilusión de la reconstrucción: el caso de La consagración de la primavera de Dominique Brun en Carozzi, M. J. coord. Escribir las danzas. Coreografías de las Ciencias socia- les. (pp. 141-176). Buenos Aires: Ed. Gorla. https://www.academia.edu/25582756/ El_Cuerpo-archivo_y_la_llusión_de_la_Reconstrucción el_caso_de la Consaḡación de_la Primaverā de Dominique. Brun [consulta: 27 mayo 2019$]$ ].

Fernandez De Larrinoa, R. Blog. Historia de la música. [en línea] https://historiamusicabinissalem.wordpress.com/ Https://bustena. wordpress.com/2015/04/20/debussy-preludio-a-la-siesta-de-un-fauno-analisis/ [Consulta: 25/08/2019]

Formis, B. (2017). La performance aquí y entonces en Copeland, M. Coreografiar exposiciones. (pp.71-90). Madrid: CA2M Centro de arte dos de mayo,

Franko, M. (2017). Introduction: The Power of Recall in a Post-Ephemeral Era en Franko, M. (Ed.), The Oxford Handbook of Dance and Reenactment. pp. 1-18. Oxford: Oxford University Press.

Gabner, H. (2009). La danza de los colores y las formas en WAA. La danza de los colores. En torno a Nijinsky y la abstracción. pp. 29-58. Fundación Mapfre. Catálogo de la exposición. Madrid: Fundación Mapfre.

Garafola, L. (2000). Ballets rusos y ballets suecos en El teatro de los pintores en la Europa de las vanguardias. pp. 37-44. Madrid: Museo Nacional Centro de Arte Reina Sofía. Ministerio de Educacion, Cultura y Deporte.

Guasch, A. M. (2015). Arte y archivo. 19202010. Genealogías, tipologías y discontinuidades. Madrid: Akal, (1ºd. 2011 ).

Hernandez, F. (2008). "La investigación basada en las artes". Educatio s. XXI. No 26. pp. 85-128. https://revistas.um.es/educatio/article/view/46641 [Consulta: 25/08/2019]

LEPECKI, A. (2013). El cuerpo como archivo: el deseo de recreación y las supervivencias de la danza en Naverán, I. y Écija, A. Lecturas sobre danza y coreografía. Madrid. Artea. pp. 61-82. https://es.scribd.com/ doc/303238358/Lepecki-El-Cuerpo-Como-Archivo-Lecturas

López-Sáez, M. C. (2018). Fenomenología de la danza: Merleau-Ponty versus Sheets-Johnston en Arte, Individuo y Sociedad. No 30. pp. 467-481. Madrid: Ediciones Complu- 
tenses. Https://revistas.ucm.es/index.php/ ARIS/article/view/57686/4564456548046 [Consulta: 20/09/2019]

Nijinsky, R. (1983). Vida de Nijinsky. Barcelona: Destinolibro 192.

Nijinsky, V. (1993). Diario. Barcelona: Ediciones Parsifal.

Pouillaude, F. (2009). Le désœuvrement chorégraphique. Etude sur la notion d'œuvre en danse. Paris: Vrin, coll: Essais d'art et de philosophie.

Siegmund, G. (2017). Affect, Technique, and Discourse -being actively passive in the face of History: Reconstruction of Reconstruction en Franko, M. (Ed.) The Oxford Handbook of Dance and Reenactment. pp. 471-486. Oxford: Oxford University Press. 